\title{
Membrane filtration media for the enumeration of coliform organisms and Escherichia coli in water: comparison of Tergitol 7 and lauryl sulphate with Teepol 610
}

\author{
By a Jonnt Commitee* of the Publio Healtu Laboratory Service and the \\ Standing Comamte of Analysts $\nmid$
}

(Received 17 July 1979)

\section{SUMDLARY}

In a multi-laboratory trial with the mombrane filtration technique, three surfactants - Teopol 010 (T610), Tergitol 7 (T7) and sodium lauryl sulphate (LS) wero compared in media for the enumeration of coliform organisms and Escherichia coli in water. A total of 179 samples of water ( 87 raw and 92 marginally chlorinated) wero examined for colony counts of coliform organisms, and 185 water samples (94 raw and 01 marginally chlorinated) for $E$. coli. Slight differences in the confirmed colony counts between the three medin were noted, but fow of these were observed consistently in overy laboratory. In most laboratories, T7 gavo slightly higher counts of $E$. coli than LS with chlorinated waters; a higher incidence of falso-positive results for $E$. coli at $44^{\circ} \mathrm{C}$ was also noted with T7. As there were no outstanding differences in the trial, sodium lnuryl sulphate, which is chemically defined, cheap and readily available, is thereforo recommended for uso at a concentration of $0.1 \%$ instead of 'Teopol 010 in the standard medium for the enumeration of coliform organisms and $E$. coli in water by $t^{2}$ membrane filtration techniquo.

\section{INTRODUCTION}

The membrane filtration technique is now used as a routine in many laboratories in the United Kingdom for the enumeration of Escherichia coli and other coliform organisms in water. Tho medium currently recommended for this purpose in Report No. 71 on 'The Bacteriological Examination of Water Supplies' is membrane enriched teepol broth (Report, 1960). Howover, production of Teepol 010,

- 'Tho Joint Committeo consisted of members of tho Water Committoo of tho Public Health Laboratory Servico and Panol 7.3A of the Standing Committeo of Analysts. The members responsiblo for this work, and thoir amilintion, woro: Dr G. I. Barrow, PHLS Truro (Chairman); Dr J. A. Rycroft, PHLS Cholmsford (Secretary); Dr J. Dadswoll, PHLS Reading; Mfr A. Godfreo, Wessex Water Authority, Bridgwater; Dr MI. Hutchinson, South West Water Authority, Exoter; Mr F. Jones, North West Water Authority, Warrington; Dr E. B. Pike, Water Research Contro, Stovenago; Dr J. W. Ridgway, Water Research Centro, Medmenliam; Miss J. K. Stovens, Thames Water Authority, London; Dr H. E. Tillott, Statistician, PHLS, Colindalo; Miss J. MI. Watkinson, PHLS Manchester, and Dr A. E. Wright, PHLS Gloucester.

† Tho Standing Committco of Analysts is a joint technical committoo of the Department of the Environment and tho National Water Council.

Requests for reprints should bo addressed to Dr J. A. Rycroft, Public Health Laboratory, Now Writtlo Street, Chelmsford CMI2 0QH. 
the particular blend of surfactant used in this medium, ceased in 1076 and supplies are now limited. A suitable alternative surfactant is therefore essential. Following preliminary work with a number of such agents, Tergitol 7 and lauryl sulphato - both widely used elsewhere for water examination - were chosen for comparison with Teepol 010 in a multi-laboratory trial. The results of this work are described in this paper.

\section{MLATERIALS AND MLETHODS}

\section{Mredia}

Comparative media trials were designed in which Tergitol 7 or sodium lauryl sulphate replaced Teepol 010 in the standard medium $-0.4 \%$ membrano enriched teepol broth (Oxoid MLI300) - described in Report No. 71 (1000). The threo media, T7, LS and T610 were based on the dehydrated portion of membrane enriched teepol broth (Oxoid MAM360). The LS medium was specially prepared by Oxoid Ltd, with $0.1 \%$ of pure lauryl sulphate already included. The other two media were made by adding either Teopol 010 or Tergitol 7 during reconstitution, according to the method recommended by the manufacturers for MNI300. Each of these surfactants was distributed from a singlo batch to 10 participating laboratories. Teepol 010 contrins $34 \%$ of the active constituents - secondary alkyl sulphates - and Tergitol $25 \%$; theso two medin were therefore treated similarly to give a concentration of $0.4 \%$ of these two surfactants in the final medium. Sodium lauryl sulphate however normally contains $05-00 \%$ of active constituent. For this trial, a specially puro form of sodium lauryl sulphnto (BDH No. 44244) containing $00 \%$ activo constituents was incorporated in the bulk dehydrated medium to give a final concentration of $0 \cdot 1 \%$. The participating laboratories mado up $250 \mathrm{ml}$ of ench medium and dispensed them in aliquots of $50 \mathrm{ml}$ in scrow-cnpped bottles; these were sterilized by steaming for $30 \mathrm{~min}$ on 3 consecutive dnys and then incubated at $37^{\circ} \mathrm{C}$ for $24 \mathrm{~h}$ and checked visually to exclude contamination. Thoy were then kept at room temperature in the dark. Bottles opened for uso wero discarded after 1 month.

\section{Membrane fillers and support pads}

Cellulose acetate mombranes (Oxoid) $47 \mathrm{~mm}$ in dinmotor with a pore size of $0.45 \mu \mathrm{m}$ were obtained in two largo batches. Each membrano was pre-sterilized and individually packed. Supplies of these membrane filters, together with sterilized absorbent pads (Whatman No. 17), wero distributed to each participating laborntory.

\section{Waler samples}

Samples of raw or partly treated water, mostly from surfuce sources, wero examined by all laboratories; when necessary, theso wero diluted after preliminary screening so as to yield a count of approximately 25 yellow colonies on the membranes. Samples of water chlorinated in tho laboratory were also used; theso wero prepared experimentally from raw waters by the marginal chlorination mothod 
used in previous comparative media trials (PHLS, 1968) and more recently in a comparison between minerals-modified glutamate medium and lauryl tryptose lactose broth for the enumeration of coliform organisms by the multiple tube method (PHLS/SCA, 1980). This was based on chlorination in the presence of excess ammonia at $4^{\circ} \mathrm{C}$ for a time sufficient to allow the survival of some coliform organisms including $E$. coli. Organisms stressed in this way are considered to be useful for accentuating differences between media.

\section{Incubation}

All membranes were incubated for 4 h at $30^{\circ} \mathrm{C}$ followed either by 14 h at 35 or $37^{\circ} \mathrm{C}$ for coliform organisms, or by 14 h at $44^{\circ} \mathrm{C}$ for $E$. coli.

\section{Colony counts and confirmatory lests}

Where practicable, all yellow colonies on membranes at 35 or $37^{\circ} \mathrm{C}$ were counted, and then subcultured into tubes of lactose peptone water for incubation at $37^{\circ} \mathrm{C}$. 'The tubes were examined for tho presence of ncid and gas at $24 \mathrm{~h}$, and if necessary nfter $48 \mathrm{~h}$. In nddition, they were subcultured for coloninl morphology and purity after nbout 6 h onto plates of MncConkoy and nutrient ngars for incubation overnight at $37^{\circ} \mathrm{C}$. Since some species of Acromonas also produce acid from lactose, thus giving yellow colonies on membranes with Teepol broth and red colonies on MacConkey agar, tho oxidnso test was essentinl for excluding them; it was performed on colonies from nutrient agar. Yollow colonics on membranes wero confirmed as coliform organisms if acid and gas wero produced in lactoso poptone water (LPIV), tho oxidnso test was negativo and typical red colonics wero formed on MacConkey ngar.

Yellow colonies on membranes at $44^{\circ} \mathrm{C}$ wero also counted and subcultured into lactoso poptono water for acid and gas production at $44^{\circ} \mathrm{C}$, and into tryptono water for indolo production at $44^{\circ} \mathrm{C}$. When tho work lond permitted, subcultures wero also mado from LPW onto nutrient agar for tho oxidaso test, and to MacConkey ngar for coloninl morphology and purity. Yellow colonies on theso membranes wero regarded as $E$. coli if acid and gas wero produced in $L P I V$ at $44^{\circ} \mathrm{C}$, if tho indolo reaction was positivo in TW after the addition of Kovac's reagent (Cowan, 1074) and tho oxidnso renction was negative.

If yollow colonics on membrnnes were numerous, subcultures were mado from n half, quarter or other specifio sector of the membrane. All yellow colonies from such sectors wero counted, thus eliminating possiblo bins duo to colony selection. Membranes overcrowded with colonies were rojected. The approximate numbers of pink, non-acid producing colonies on membranes were also recorded, since they can interfero with tho growth and development of yellow coliform colonies.

\section{RESULI'S}

The membrane counts of confirmed coliform organisms and $E$. coli obtained by all the lnborntories with the threo media under review - Tergitol 7 broth (T7), Inuryl sulphato broth (IS) and Tecpol broth (T010)-havo been analysed 
statistically. These results represent coliform counts from 179 water samples (87 raw and 92 chlorinated) and $E$. coli counts from 185 water samples ( 04 raw and 01 chlorinated). For the results to be acceptable, the numbers of yellow colonies on the membranes ranged from 0 to approximately 100.

\section{Comparison of T7 and LS with T610}

Tables 1 and 2 summarize the findings from different laboratories in terms of which media gave the higher confirmed colony count. Some of the laboratories examined only small numbers of samples and their results have therefore been combined. In these tables, the results between 'T610 and T'7 are compared in Section I, and between T'610 and LS in Section II.

The combined results for all laboratories ('Table 1) indicato that, for coliform organisms in raw water, 'T610 tended to give higher counts than T'7 or LS, but in chlorinated waters, I7 and LS gave higher counts moro often than T610. Tho results from individunl laboratories howover did not roveal a consistent trend.

Table 2 shows the colony counts for confirmed $E$. coli on mombranes. 'The overall results show no significant difference between pairs of medin, except that T010 gave higher counts than LS with chlorinated waters moro often than it gavo lower counts. 'This finding however was mainly influenced by tho results from ono laboratory. 'Tho samo laboratory also found that 'T'010 gavo higher counts than I'7 with chlorinated waters, but other laboratories found tho roverso - higher counts with $\mathrm{T} 7$ - and the differences thus cancelled ench other out in the combined results.

\section{Comparison between T'7 and LS}

The confirmed coliform results aro summarized in Section III of 'I'ablo 1. 'Theso show that the number of samples in which I'7 gavo higher colony counts on mem. branes than LS is very nearly the same as for those in which LS gavo higher counts than T7 (36:38). No individual lnboratory found a significant differenco botween the two medin; with chlorinnted waters especially, the results wero uniform.

The confirmed $E$. coli results are summarized in Section III of 'T'able 2. There is some evidence that T7 gave higher colony counts than LS more often than it gave lower counts, especially with chlorinated waters. But this differenco between the media was not apparent in every participating laboratory.

The actual results of confirmed coliform and $E$. coli colony counts aro shown in Figs. 1 and 2. For clarity, the counts aro plotted on a logarithmic scalo with zero readings on the axes. The diagonal lines on the graphs represent equal counts with the two media shown. There is some sentter about theso lines throughout the range of counts, indicating that comparison between tho two media is the same regardless of how many organisms were present. The scatter of results is somewhat greater for chlorinated than for raw water samples.

Although Tablo 2, Section III shows that T'7 gavo moro $E$. coli counts which were higher than those given by LS than vico versa, Figs. 1 and 2 show that tho concentration of points below tho diagonal lines (i.e. samples whero the T7 count exceded the LS count) nro not strikingly different from those abovo tho lines. 


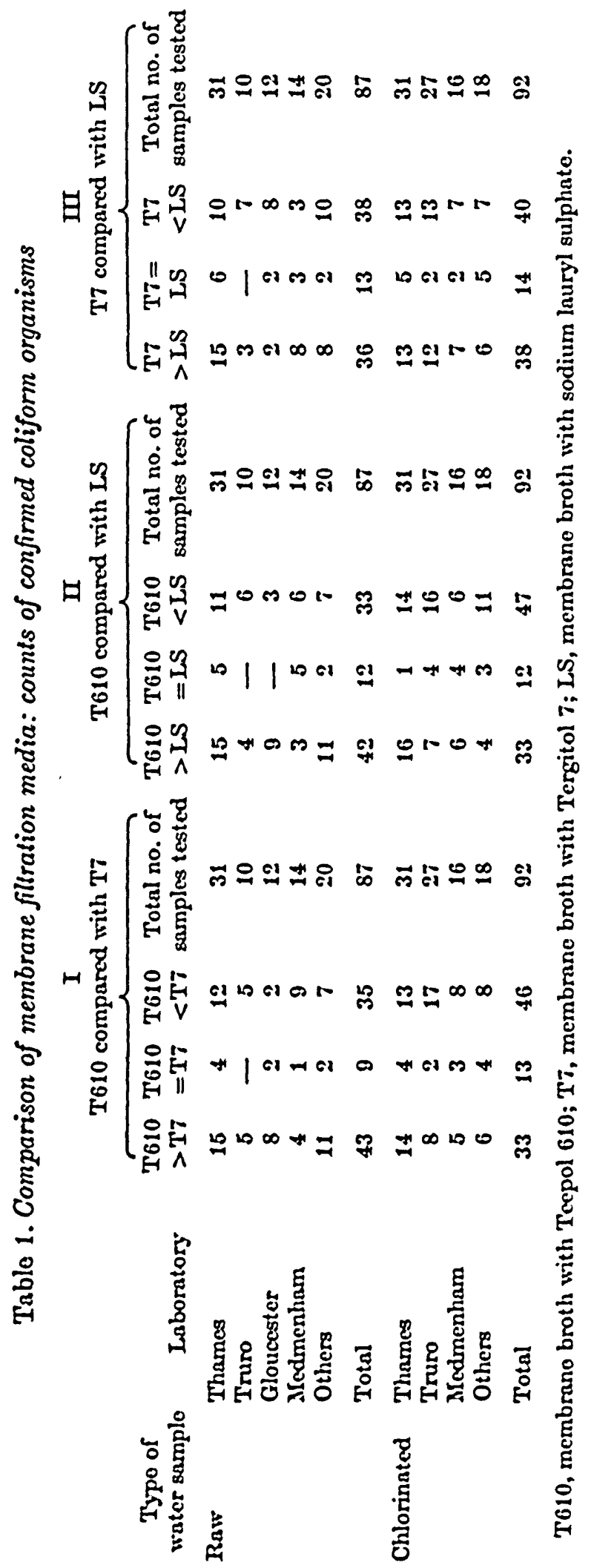




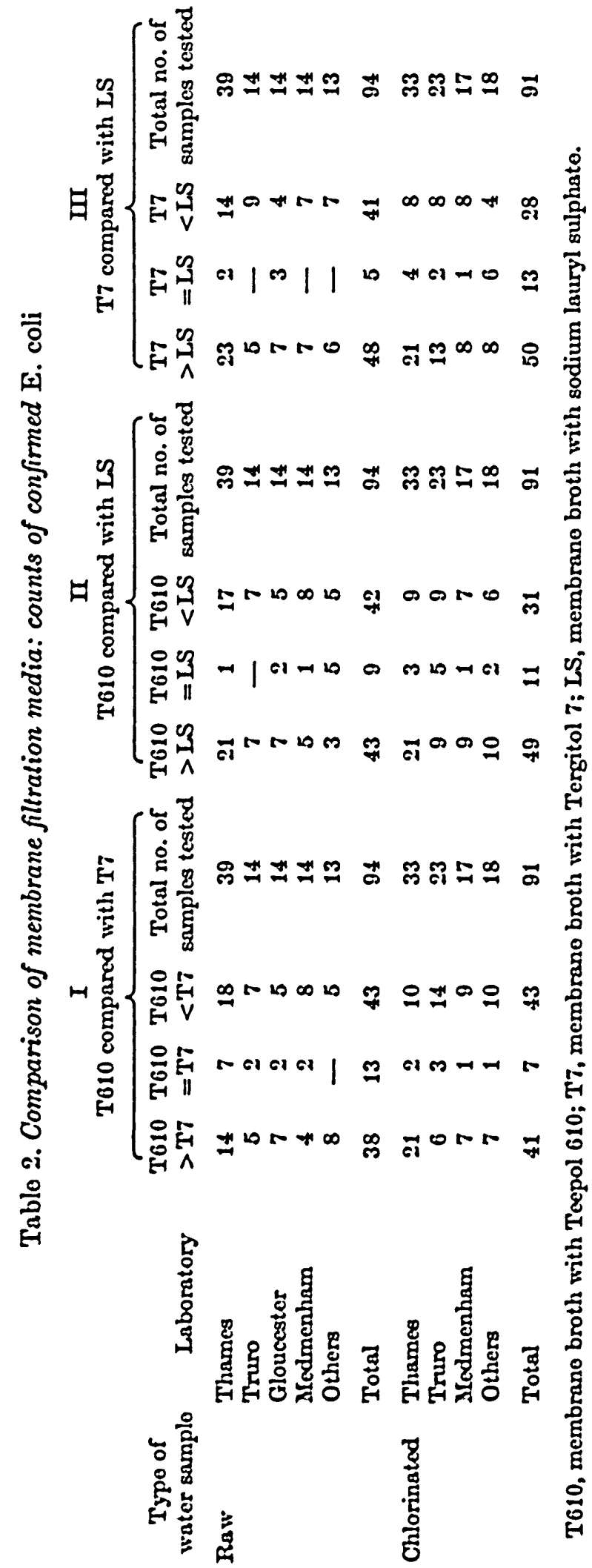


Raw

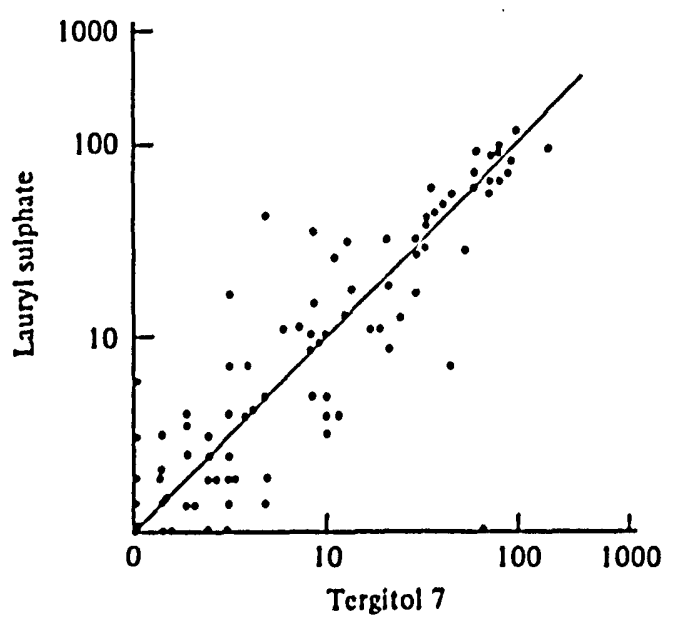

Chlorinated

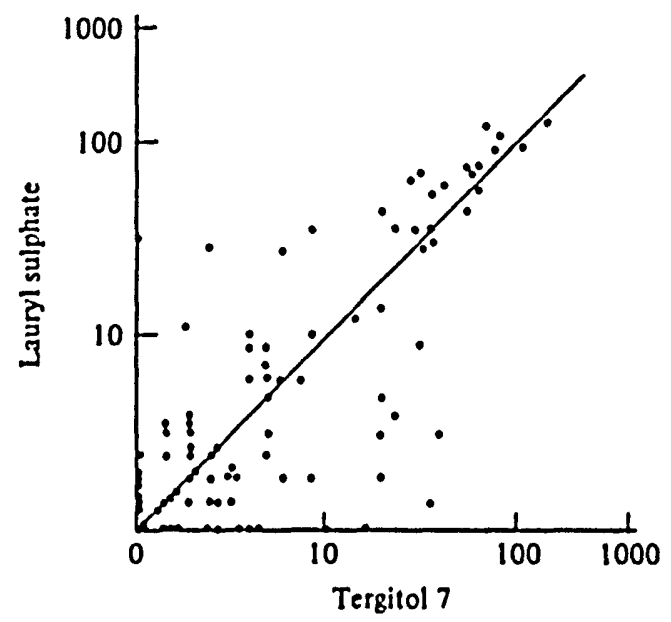

Fig. 1. Confirmod coliform results for T7 and LS mombrano filtrntion modia with raw and chlorinatod wators.
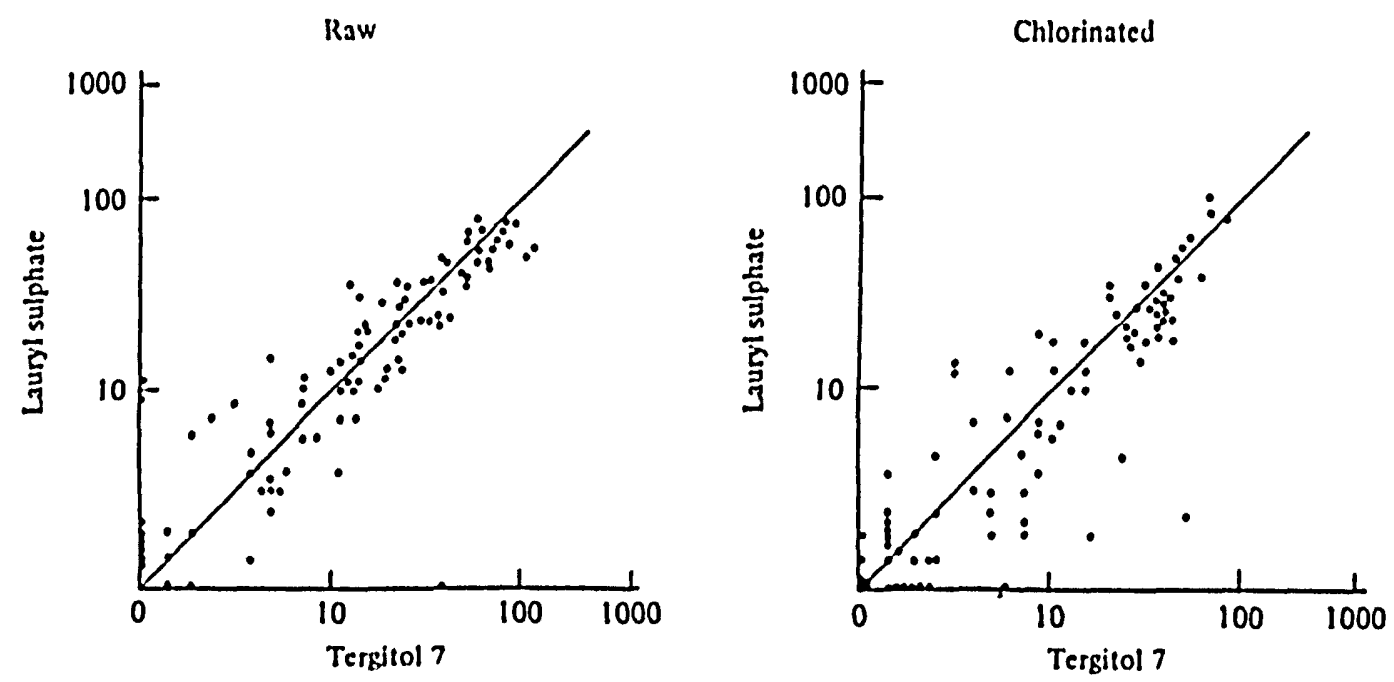

Fig. 2. Confirmed E. coli resulta for T7 and LS membrano filtration modia with raw and chlorinated wators.

\section{Coliform counts at 35 and $37^{\circ} \mathrm{C}$}

Soven laboratories incubated membranes for coliform organisms at $37^{\circ} \mathrm{C}$ and threo laborntories at $35^{\circ} \mathrm{C}$. There was no difference between these two sets of laboratories in their conclusions about the comparison between T7 and LS. One Inborntory exnmined duplicato sets of samples at both temperatures. Again, there was no significant difference between the membrano counts at either temperature; howover, only 10 raw and 10 chlorinated samples wero used and theso all camo from one source. 
Table 3. Water samples yielding false-negative results* with T610, T7 and LS

\begin{tabular}{cl}
$\begin{array}{c}\text { Temperature } \\
\text { of } \\
\text { incubation }\end{array}$ & \multicolumn{1}{c}{$\begin{array}{r}\text { Typo of } \\
\text { water } \\
\text { samplo }\end{array}$} \\
$35 / 37^{\circ} \mathrm{C}$ & $\begin{array}{l}\text { Raw } \\
\text { Chlorinated }\end{array}$ \\
$44^{\circ} \mathrm{C}$ & $\begin{array}{l}\text { Raw } \\
\text { Chlorinated }\end{array}$
\end{tabular}

\begin{tabular}{crrr}
$\begin{array}{c}\text { Total no. } \\
\text { of samples } \\
\text { tested }\end{array}$ & \multicolumn{3}{c}{$\begin{array}{c}\text { Falso negativo } \\
\text { results }\end{array}$} \\
\cline { 2 - 4 } 87 & T610 & T7 & LS \\
02 & 0 & 6 & 7 \\
04 & 10 & 11 & 13 \\
01 & 3 & 8 & 3 \\
& 0 & 0 & 14
\end{tabular}

- Falso-negativo water results are definod as thoso in which a water samplo gave oither (i) no yellow colonies, or (ii) only yellow colonies which did not confirm as coliform organisms or $E$. coli when one or both of tho other media gavo yellow colonics which did confirm.

'T610, membrano broth with 'Teepol 010; T7, membrano broth with 'Tergitol 7; LS, mom. brano broth with sodium lauryl sulphato.

\section{Water samples giving false-negative results}

Table 3 shows the falso-negative results given by the three media. $A$ falsonegative result for a water sample with one medium means that it gave $a$ nil count when one or both of the other medin yielded confirmed coliform organisms. A nil count was recorded either when no yellow colonies developed on the membrane, or when there were only yellow colonies which could not be confirmed as coliform organisms. No significant differences in false-negative rates were found between the three media, although the incidence of false-negative results tended to be higher with chlorinated than with raw water samples.

\section{False-positive membrane colony resulls}

These are defined as yellow colonies on membranes which failed to confirm as coliform organisms at $35^{\circ}$ or $37^{\circ}$ or as $E$. coli at $44^{\circ} \mathrm{C}$. The rate of such falsepositive membrane results varied considerably between laboratories. For example, at one laboratory the incidence of false-positive results among coliform counts averaged $85 \%$ whereas in another laboratory it was only $0 \%$. The results for all laboratories for each medium are shown in Tablo 4. For raw waters, no laboratory found any difference between the rate of false-positive results both for coliform organisms and $E$. coli with any medium. With chlorinated waters, however, overy laboratory obtained a slightly higher rate of false-positive results at $44^{\circ} \mathrm{C}$ with $\mathrm{T} 7$ than with LS, thus making the combined results significant with Cochran's statistical test. For coliform organisms, the overall rate of false-positive results was higher with T7 - but this was due mainly to results from one laboratory; all other laboratories found little or no difference so that, applying Cochran's test to the combined results, there was no significant difference between these two medin. False-positive rates with T610 were usually intermediate between T7 and LS. 


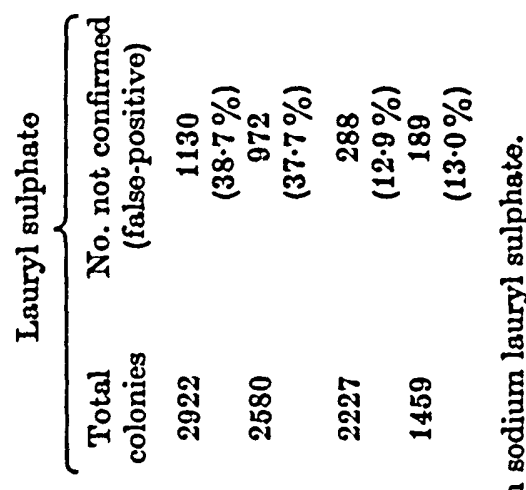

(

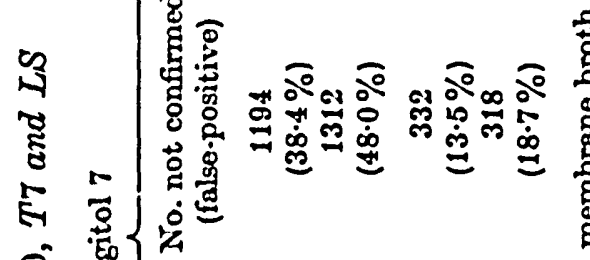



स

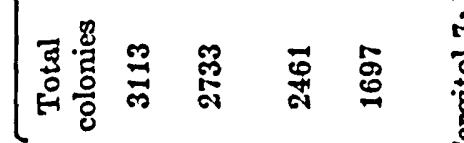

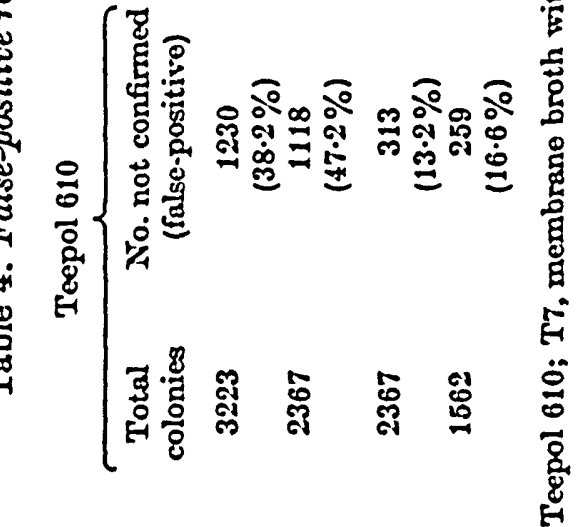

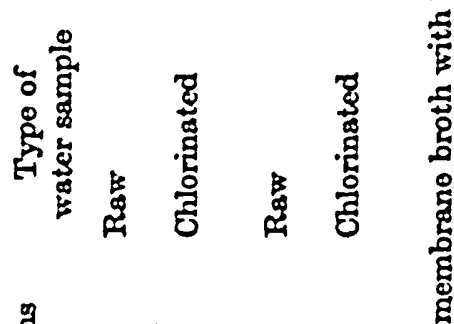

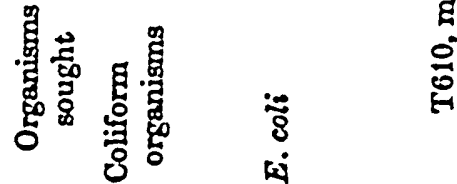




\section{DISCUSSION}

Almost from the start of the trial, it seemed that there were no outstanding differences in the performance of the three media for the enumeration of coliform organisms or $E$. coli on membranes. With regard to coliform organisms, T610 tended to give higher membrane colony counts than T7 or LS with raw waters, whilst with marginally chlorinated waters, T7 and LS tended to give higher counts than T610. There was excellent agreement between the counts obtained on T7 and LS with chlorinated waters. For $E$. coli in raw waters, there was littlo to choose between the three media, although T7 tended to give slightly higher counts. With chlorinated waters, T7 again tended to give the higher counts, although one laboratory found considerably higher counts with T610; in all laboratories, LS consistently gave the lowest counts. Statistical analysis of the observed differences between the three media did not, however, reveal any clear-cut conclusion. The choice between LS and T7 as a replacement for T010 in membrane enriched teepol broth (Report, 1969) therefore depended on other factors.

The rate of false-negative results - either (i) no yellow colonies or (ii) yellow colonies none of which could be confirmed as either coliform organisms or $E$. coli when these were present on one or both of the other two media - tended to bo higher with chlorinated than with raw water samples, but there was no significant difference between the three media. The incidence of false-positive results - that is the proportion of yellow colonies on membranes which did not confirm as coliform organisms at $35 / 37^{\circ} \mathrm{C}$ or as $E$. coli at $44^{\circ} \mathrm{C}$ - varied greatly between laboratories, probably reflecting the different bacterial content of the various water samples examined. However, when the combined results for raw water samples from all laboratories were analysed, there was no significant difference in the incidence of yellow colonies which failed to confirm from the three media. But with chlorinated water samples at $44^{\circ} \mathrm{C}$, the incidence of colonies which failed to confirm as $E$. coli was significantly higher with $\mathrm{T} 7$ than with LS.

Both T610 and T7 are mixtures of surfactants controlled by specified manufacturing processes; the commercial production of T610 ceased in 1076, and if T7 were to be recommended as an alternative to T010, a similar problem might arise if this too were discontinued. On the other hand, specially pure LS is chemically defined, cheap and can be obtained as a powder which contains $90 \%$ of activo constituents. It can thus be incorporated in a dehydrated medium. In contrast, both T610 and T7 have to be added separately to the media during reconstitution. Moreover T7 broth is usually turbid which could lead to batches of medium being discarded in error because they appeared contaminated.

In some laboratories colonial differentiation, especially the acid reaction, was considered to be much better with IS than with T7. Two laboratories also noted that, on incubation for coliform organisms, spreading of the colonies on membranes occurred less with LS than with T7. Although there were no outstanding differences between the numbers of pink, non-acid-producing colonies which grew on membranes with the three media, somo laboratories noted fower of such interfering colonies with LS. 
Although the medium containing LS tended to give slightly lower counts of $E$. coli in chlorinated waters, this is not regarded as a great disadvantage, as there is in practice simultaneous examination for coliform organisms, and LS was found to be as successful as T7 for the isolation of these organisms in chlorinated waters. For all these reasons, and especially since it is cheap, readily available, chemically defined and can be incorporated directly in media before dehydration, lauryl sulphate $(0.1 \%)$ is recommended as a substitute for T010 in membrane enriched broth for the enumeration of coliform organisms and $E$. coli in water by the membrane filtration technique. However, T7 ( $0.4 \%)$ also gives satisfactory results, and if necessary, it may be used as an alternative.

This work was partly funded by the Department of the Environment through Research Contract DGR/480/481.

\section{REFERENCES}

Cowss, S. T. (1074). Cowan \& Stccl's Manual for the Identification of Medical Bacteria, 2nd ed., p. 175. Cambridgo Univorsity Press.

Punlio Healtur Lamoratory Servioe Standina Committee on time Bacteriological Examination of Water Supplies (1908). Comparison of MacConkoy broth, Teopol broth and glutamic acid modia for tho onumoration of coliform organisms in wator. Journal of Hygiene 66, 07.

Joint Commitree of mie Punlio Healtit Lanonatory Service and tme Standina Com. MitTEe of ANALYsts (1080). A comparison betweon Mlinerals-Modifiod Glutamato Modium and Lauryl Tryptoso Lactoso Broth for the enumoration of Escherichia coli and coliform organisms in wator by tho Multiplo Tubo mothod. Journal of Hygiene 85, 35.

Repont (1000). The Bactoriological Examination of Water Supplics. Roports on Public Health and Medical Subjocts No. 71, HMSO, London. 